\title{
Doses e Épocas de Aplicação de Regulador de Crescimento em HÍBRIDOS DE MILHO ${ }^{1}$
}

\author{
Rates and Times of Growth Regulator Application on Corn Hybrids \\ ZAGONEL, J. ${ }^{2}$ e FERREIRA, C. ${ }^{3}$
}

\begin{abstract}
RESUMO - A fim de avaliar o efeito do regulador de crescimento trinexapac-ethyl em diferentes doses e épocas de aplicação em dois híbridos de milho, instalaram-se dois experimentos em Ponta Grossa, PR, Brasil, no ano agrícola de 2010/11. O delineamento experimental foi o de blocos ao acaso, em esquema fatorial 4 x 4 (doses x épocas de aplicação), com quatro repetições. Os tratamentos constaram da aplicação do trinexapac-ethyl (Moddus ${ }^{\circledR}$ ) nas doses de 0,0, 187,5, 375,0 e 562,5 g ha-1 nos estádios V2, V4, V6 e V8 do milho, nos híbridos Status TL e Maximus TLTG. Avaliaram-se características agronômicas, componentes de produção e produtividade. A época de aplicação do trinexapac-ethyl não afetou características agronômicas e a produtividade dos dois híbridos de milho. Em relação à dose do regulador, somente o Maximus TLTG mostrou aumento da largura e diminuição do comprimento das folhas com o incremento da dose do produto, sem efeitos substanciais nos componentes da produção e na produtividade. Os resultados mostraram pouca resposta dos híbridos avaliados à dose e época de aplicação do trinexapac-ethyl; ao contrário do trigo, o uso na cultura deve ser mais bem avaliado, especialmente em relação à dose do produto e à reação de híbridos.
\end{abstract}

Palavras-chave: trinexapac-ethyl, Zea mays, produtividade.

\begin{abstract}
Aiming to evaluate the effect of different rates and application times of the growth regulator trinexapac-ethyl on two corn hybrids, two experiments were carried out in Ponta Grossa, PR, Brazil, in the agricultural year 2010/2011. The experimental design was arranged in randomized blocks in a factorial scheme $4 \times 4$ (rates $x$ time) with four replications. Treatments consisted of application of trinexapac-ethyl (Moddus $\left.{ }^{\circledR}\right)$ at the rates of $0.0,187.5,375.0$, and $562.5 \mathrm{~g} \mathrm{ha}^{-1}$ and corn stages V2, V4, V6 and V8 of the hybrids Status TL and Maximus TL TG. The agronomic traits yield and yield components were evaluated. Time of application of trinexapac-ethyl did not affect yield and agronomic characteristics of the two corn hybrids. In relation to the regulator rate, only Maximus $T L T G$ responded to increased product rate, with increased leaf width and length, without substantial effects on yield and yield components. The hybrids showed little dose response to rate and time of application of trinexapac-ethyl; unlike wheat, the use of the culture should be further evaluated, especially in relation to the amount of the product and the reaction of the hybrids.
\end{abstract}

Keywords: trinexapac-ethyl, Zea mays, yield.

\section{INTRODUÇÃO}

A cultura do milho (Zea mays) desempenha papel fundamental no sistema de produção brasileiro e mundial (Dourado Neto et al., 2004). O emprego de técnicas modernas tem proporcionado aumento da produtividade de grãos do milho; a exploração da capacidade de rendimento de grãos é possivel mediante o desenvolvimento de técnicas que propiciem o aproveitamento dos recursos do meio.

Em milho de alta produtividade, em geral, são utilizadas altas populações de plantas e

Recebido para publicação em 27.7.2012 e aprovado em 25.11.2012.

2 Eng-Agro ${ }^{-}$, D.Sc., Professor Associado, Dep. de Fitotecnia e Fitossanidade, Universidade Estadual de Ponta Grossa - UEPG,

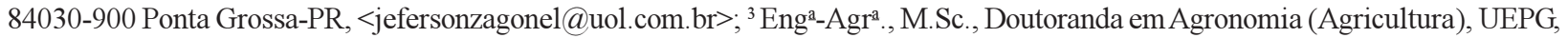
Ponta Grossa-PR, <cferreira87@hotmail.com> 
elevadas doses de nitrogênio. No entanto, com o aumento da população e da dose de nitrogênio, consequentemente ocorre aumento da estatura de plantas e da altura de inserção das espigas, tornando as plantas mais suscetiveis ao acamamento e quebramento, o que pode resultar em perdas significativas em híbridos suscetiveis e/ou em condições de clima favoráveis ao acamamento (Duete et al., 2008).

Para possibilitar o uso de maiores densidades de semeadura e doses de nitrogênio, sem que ocorra o acamamento, devem-se utilizar cultivares de porte baixo. No entanto, nem sempre esses cultivares estão disponiveis ou são adaptados à região de cultivo, o que exige o uso de técnicas alternativas. Entre essas encontra-se o uso de reguladores de crescimento, que são utilizados amplamente em trigo, com excelentes resultados não só no sentido de evitar o acamamento, como também pelos efeitos na arquitetura de plantas, $o$ que permite maior absorção da radiação solar e, consequentemente, maior produtividade de grãos (Zagonel et al., 2002a; Zagonel \& Fernandes, 2007).

O trinexapac-ethyl (Moddus ${ }^{\circledR}$ ) é um regulador de crescimento que tem sido bastante empregado na cultura de trigo no Brasil, com o principal objetivo de evitar e/ou prevenir o acamamento. O produto atua nas plantas, reduzindo a elongação celular no estádio vegetativo, interferindo no final da rota metabólica da biossíntese do ácido giberélico (Rajala, 2003) pela inibição da enzima $3 \beta$-hidroxilase, reduzindo drasticamente o nível do ácido giberélico ativo $\left(\mathrm{GA}_{1}\right)$ e, assim, aumentando acentuadamente seu precursor biossintético imediato $\mathrm{GA}_{20}$ (Davies, 1987). A queda no nível do ácido giberélico ativo $\left(\mathrm{GA}_{1}\right)$ é a causa da diminuição do crescimento das plantas (Rademacher, 2000).

Em milho, não há na literatura relatos do uso do trinexapac-ethyl, porém, na cultura do trigo, em experimentos realizados na Argentina foi observada diminuição da área foliar, sem diminuição na atividade fotossintética. As aplicações de trinexapac-ethyl com o primeiro ao terceiro nó visivel provocaram mudanças na densidade de espigas, promovendo o desenvolvimento dos perfilhos e aumento da produção. A aplicação no início da elongação do colmo provocou mudanças na sua anatomia, aumentando o diâmetro do caule e a espessura da parede celular (Lozano \& Leaden, 2002). No Brasil, Zagonel et al. (2002a) avaliaram o trinexapac-ethyl no cultivar de trigo OR-1, de porte baixo, e verificaram redução do comprimento dos entrenós e aumento do número de espigas por metro e da produtividade. Em outro experimento, no mesmo local, Zagonel et al. (2002b), utilizando o cultivar IAPAR 53, de porte médio/alto, também verificaram redução substancial da altura das plantas com o aumento da produtividade. Lozano \& Leaden (2002), avaliando o trinexapac-ethyl em dois cultivares de trigo, também observaram ganhos de $27 \%$ na produtividade.

Os resultados observados para o trigo mostram efetividade do trinexapac-ethyl em afetar as plantas. Esse sucesso também é obtido em aplicações realizadas em gramados, como no trabalho de Costa et al. (2009), que, estudando quatro espécies de gramas, obtiveram retardamento do crescimento vegetativo e redução na necessidade de cortes em todas as espécies pesquisadas. Já em milho, o produto vem sendo utilizado experimentalmente, porém as respostas não são frequentes e variam em função de fatores como clima, cultivar, dose e época de aplicação.

Nesse sentido, realizaram-se dois experimentos com o objetivo de avaliar os efeitos do trinexapac-ethyl, em diferentes doses e épocas de aplicação, em dois híbridos de milho BT: um suscetivel e outro tolerante ao glifosato.

\section{MATERIAL E MÉTODOS}

Dois experimentos foram instalados no municipio de Ponta Grossa - PR $\left(25^{\circ} 5^{\prime} 49^{\prime \prime} \mathrm{S}\right.$, $50^{\circ} 3^{\prime} 11^{\prime \prime} \mathrm{W}$ e altitude de $\left.1.025 \mathrm{~m}\right)$, no ano agrícola de 2010/11. O solo no local é classificado como Cambissolo háplico distrófico de textura argilosa. A análise química do solo, em amostragem de 0 a $10 \mathrm{~cm}$, revelou os seguintes resultados: $\mathrm{pH}\left(\mathrm{CaCl}_{2}\right)=5,0 ; \mathrm{Ca}^{++}=$ $4,0 \mathrm{cmol}_{\mathrm{c}} \mathrm{dm}^{-3} ; \mathrm{Ca}+\mathrm{Mg}=6,5 \mathrm{cmol}_{\mathrm{c}} \mathrm{dm}^{-3} ; \mathrm{K}=$ $0,52 \mathrm{cmol}_{\mathrm{c}} \mathrm{dm}^{-3} ; \mathrm{P}=11,1 \mathrm{mg} \mathrm{dm}^{-3} ; \mathrm{C}=38 \mathrm{~g} \mathrm{dm}^{-3}$; $\mathrm{H}+\mathrm{Al}=6,21 \mathrm{cmol}_{\mathrm{c}} \mathrm{dm}^{-3} ; \mathrm{Al}^{+++}=0,0 ; \mathrm{CTC}=13,23$; $\mathrm{V} \%=53$; e a análise granulométrica, em $\mathrm{g} \mathrm{kg}^{-1}$ : argila - 460; silte - 179; areia - 361 . 
O delineamento experimental foi o de blocos ao acaso, em esquema fatorial $4 \times 4$ (épocas de aplicação $\mathrm{x}$ doses), com quatro repetições. As parcelas apresentaram área total de $28,8 \mathrm{~m}^{2}(6,0 \times 4,8 \mathrm{~m})$ e área útil de $16,0 \mathrm{~m}^{2}$ $(5,0 \times 3,2 \mathrm{~m})$.

Os tratamentos constaram de quatro doses do trinexapac-ethyl $(0,0,187,5,375,0$ e $\left.562,5 \mathrm{~g} \mathrm{ha}^{-1}\right)$, correspondente a $0,00,0,75,1,50$ e 2,25 $\mathrm{L} \mathrm{ha}^{-1}$ do produto comercial Moddus ${ }^{\circledR}$, repectivamente, aplicadas em quatro épocas (V2, V4, V6 e V8), em dois experimentos: um com o híbrido de milho Status TL e outro com o Maximus TLTG. O Status TL é um híbrido simples, de ciclo precoce e variável de 70 a 75 dias para o florescimento e de 150 a 165 dias para a colheita. O híbrido Maximus TLTG é tolerante ao glifosato, possui a mesma duração de ciclo do Status TL, além de se caracterizar pela aptidão para produção de silagem (Cruz et al., 2010).

O sistema de semeadura foi o plantio direto na palha, sobre resteva de trigo. A semeadura de ambos os híbridos foi realizada mecanicamente no dia 24/11/2010, em fileiras espaçadas de $0,8 \mathrm{~m}$, colocando-se em média seis sementes por metro de fileira. A emergência ocorreu no dia 30/11/2010. A adubação consistiu da aplicação de $350 \mathrm{~kg}^{\text {ha-1 }}$ de 10-2020 , na semeadura, e $62,5 \mathrm{~kg} \mathrm{ha}^{-1}$ de nitrogênio, na forma de ureia, aplicado em cobertura nos estádios V2 e V4 do milho.

O trinexapac-ethyl foi aplicado por meio de pulverizador costal, à pressão constante de $30 \mathrm{lb} \mathrm{pol}{ }^{-2}$, pressurizado por $\mathrm{CO}_{2}$ comprimido, munido de seis pontas com bicos de jato plano "leque" XR 110-015, calibrado para volume de calda proporcional a $150 \mathrm{~L} \mathrm{ha}^{-1}$.

No florescimento, foram determinados, em oito plantas das duas fileiras centrais de cada parcela, a altura de plantas e de inserção da espiga; o diâmetro do colmo, com o auxílio de paquímetro digital; a largura e comprimento da folha superior à espiga e da folha oposta à espiga; e a área foliar por planta, avaliando-se todas as folhas de cinco plantas por parcela, através do determinador de área foliar da marca L-COR, modelo LI-3100C.

Foi calculado o índice de acamamento pelo método proposto por Sousa (1998), avaliando-se visualmente, em cada parcela, a porcentagem e o grau de acamamento. Foram realizadas duas avaliações: uma quando se verificou a ocorrência do acamamento, no estádio R3 do milho e na pré-colheita. Na época da colheita, foram determinados a população final e o número de espigas por planta, utilizando-se oito plantas das duas fileiras centrais das parcelas. $\mathrm{Na}$ mesma época ainda foram determinados os componentes de produção, pela colheita das espigas em $2 \mathrm{~m}$ de fileira da área útil de cada parcela, e a produtividade, pela massa dos grãos da área útil das parcelas, corrigida para $13 \%$ de umidade.

Os dados obtidos foram submetidos à aplicação do teste $\mathrm{F}$ na análise da variância. Quando significativas, as médias das épocas de aplicação foram comparadas pelo teste de Tukey a $5 \%$ de probabilidade. As doses foram comparadas por regressão polinomial.

\section{RESULTADOS E DISCUSSÃO}

Os híbridos de milho foram analisados separadamente, visto que a recomendação não pode ser ampla no caso de uma cultura que é cultivada numa diversidade de híbridos, sejam simples, duplos, triplos e variedades. Além disso, a tendência atual é o manejo por cultivar, como é feito em outras culturas. No caso do trigo, como exemplo, a recomendação de uso do trinexapac-ethyl é feita por cultivar, adequando-se a dose à resposta da produtividade dele, independentemente da resposta ao acamamento (Zagonel \& Fernandes, 2007).

A altura de plantas é a principal característica que um regulador de crescimento deve alterar nas plantas. No trabalho de Fialho et al. (2009) com Brachiaria brizantha, além de a aplicação de trinexapac-ethyl reduzir a estatura das plantas, também diminuiu o comprimento do limbo foliar, do entrenó e da bainha. Espindula et al. (2010), comparando doses e épocas de aplicação de três reguladores de crescimento na elongação do colmo de plantas de trigo, observaram que o trinexapac-ethyl foi o que promoveu menor comprimento de colmo nas plantas. No presente trabalho, tanto para o híbrido Status TL quanto para Maximus TLTG, a altura de inserção de espigas e a altura de plantas não foram afetadas pelo trinexapac-ethyl, independentemente da época de aplicação (Tabelas 1 e 2). 
Tabela 1 - Altura das plantas (AP), altura de inserção da espiga (AE), diâmetro do colmo (DC), área foliar por planta (AF) e índice de área foliar (IAF) do milho, Status TL e Maximus TL TG, em função de épocas de aplicação de trinexapac-ethyl. Ponta Grossa-PR, 2011

\begin{tabular}{|c|c|c|c|c|c|}
\hline \multirow{2}{*}{ Época de aplicação } & \multicolumn{5}{|c|}{ Status TL } \\
\hline & $\mathrm{AP}(\mathrm{m})$ & $\mathrm{AE}(\mathrm{m})$ & $\mathrm{DC}(\mathrm{mm})$ & $\mathrm{AF}\left(\mathrm{cm}^{2}\right)$ & IAF \\
\hline $\mathrm{V} 2$ & $2,8 \mathrm{a}$ & $1,6 \mathrm{a}$ & $23,3 \mathrm{a}$ & $6.977,4 \mathrm{a}$ & $5,3 \mathrm{a}$ \\
\hline $\mathrm{V} 4$ & $2,8 \mathrm{a}$ & $1,6 \mathrm{a}$ & $23,9 \mathrm{a}$ & $6.786,8 \mathrm{a}$ & $5,0 \mathrm{a}$ \\
\hline V6 & $2,8 \mathrm{a}$ & $1,6 \mathrm{a}$ & $23,6 \mathrm{a}$ & $6.923,8 \mathrm{a}$ & $5,2 \mathrm{a}$ \\
\hline V8 & $2,8 \mathrm{a}$ & $1,6 \mathrm{a}$ & $23,3 \mathrm{a}$ & $7.016,7 \mathrm{a}$ & $5,4 \mathrm{a}$ \\
\hline \multirow[t]{2}{*}{$\mathrm{CV}(\%)$} & 4,1 & 4,8 & 6,6 & 8,3 & 11,5 \\
\hline & \multicolumn{5}{|c|}{ Maximus TLTG } \\
\hline $\mathrm{V} 2$ & $2,9 \mathrm{a}$ & $1,6 \mathrm{a}$ & $23,1 \mathrm{a}$ & $7.010,8 \mathrm{a}$ & $4,7 \mathrm{a}$ \\
\hline V4 & $2,9 \mathrm{a}$ & $1,6 \mathrm{a}$ & $23,1 \mathrm{a}$ & $6.611,1 \mathrm{a}$ & $4,5 \mathrm{a}$ \\
\hline V6 & $2,9 \mathrm{a}$ & $1,6 \mathrm{a}$ & $23,3 \mathrm{a}$ & $6.728,5 \mathrm{a}$ & $4,7 \mathrm{a}$ \\
\hline V8 & $2,9 \mathrm{a}$ & $1,5 \mathrm{a}$ & $22,6 \mathrm{a}$ & $6.786,4 \mathrm{a}$ & $4,8 \mathrm{a}$ \\
\hline CV $(\%)$ & 2,8 & 2,9 & 5,5 & 9,6 & 15,2 \\
\hline
\end{tabular}

Médias seguidas da mesma letra minúscula não diferem significativamente pelo teste de Tukey ( $\mathrm{p} \leq 5 \%$ ); $\mathrm{CV}$ : coeficiente de variação.

Ressalta-se que, além da altura de plantas e de inserção da espiga, não ocorreram interações significativas para as demais variáveis analisadas.

Alguns trabalhos não publicados indicam que a aplicação do regulador no estádio V8 do milho e doses superiores a $375 \mathrm{~g}^{\text {ha }} \mathrm{f}^{-1}$ do ingrediente ativo promovem redução de altura de alguns híbridos de milho, mas a resposta não é frequente e também varia com o ano de cultivo. Das épocas de aplicação utilizadas no presente trabalho, teoricamente, as aplicações mais tardias tenderiam a reduzir mais a altura de plantas, como no trigo, já que o trinexapac-ethyl atua nos entrenós que se formam mais tarde, os mais longos (Zagonel $\&$ Fernandes, 2007). No trigo, o crescimento dos entrenós ocorre no tecido meristemático, situado logo acima dos nós (Mundstock, 1983), onde há intensa atividade metabólica, principalmente das giberelinas, e provavelmente o crescimento dos entrenós do milho não ocorre da mesma forma, sendo a causa da resposta diferencial entre as culturas.

O diâmetro do colmo não foi afetado pelo trinexapac-ethyl no híbrido Maximus TLTG (Tabelas 1 e 2). Para o Status TL, não foi observada resposta do diâmetro do colmo em relação à época de aplicação do trinexapacethyl (Tabela 1), porém para a dose observouse resposta quadrática (Tabela 2), com
Tabela 2 - Altura de plantas (AP), altura de inserção de espiga $(\mathrm{AE})$, diâmetro do colmo (DC), área foliar $(\mathrm{AF})$ e índice de área foliar (IAF), Status TL e Maximus TLTG, em função de doses de trinexapac-ethyl. Ponta Grossa-PR, 2011

\begin{tabular}{|l|l|c|}
\hline Status TL & \multicolumn{1}{|c|}{ Equação ou média } & $\mathrm{R}^{2}$ \\
\hline $\mathrm{AP}(\mathrm{m})$ & $\hat{\mathrm{Y}}=2,8$ & $\mathrm{~ns}$ \\
\hline $\mathrm{AE}(\mathrm{m})$ & $\hat{\mathrm{Y}}=1,6$ & $\mathrm{~ns}$ \\
\hline $\mathrm{DC}(\mathrm{mm})$ & $\hat{\mathrm{Y}}=24,1-1,93 \mathrm{x}+0,839 \mathrm{x}^{2}$ & $73,4^{*}$ \\
\hline $\mathrm{AF}\left(\mathrm{cm}^{2}\right)$ & $\hat{\mathrm{Y}}=6926,1$ & $\mathrm{~ns}$ \\
\hline $\mathrm{IAF}$ & $\hat{\mathrm{Y}}=5,2$ & $\mathrm{~ns}$ \\
\hline Maximus TLTG & \multicolumn{1}{|c|}{ Equação ou média } & $\mathrm{R}^{2}$ \\
\hline $\mathrm{AP}(\mathrm{m})$ & $\hat{\mathrm{Y}}=2,9$ & $\mathrm{~ns}$ \\
\hline $\mathrm{AE}(\mathrm{m})$ & $\hat{\mathrm{Y}}=1,6$ & $\mathrm{~ns}$ \\
\hline $\mathrm{DC}(\mathrm{mm})$ & $\hat{\mathrm{Y}}=23,1$ & $\mathrm{~ns}$ \\
\hline $\mathrm{AF}\left(\mathrm{cm}^{2}\right)$ & $\hat{\mathrm{Y}}=6784,2$ & $\mathrm{~ns}$ \\
\hline $\mathrm{IAF}$ & $\hat{\mathrm{Y}}=4,7-0,64 \mathrm{x}+0,363 \mathrm{x}^{2}$ & $99,2^{*}$ \\
\hline
\end{tabular}

ns: não significativo; ${ }^{*}$ significativo a $5 \%$ de probabilidade.

tendência de diminuição inicial do diâmetro com dose mais baixa e posterior aumento deste com o aumento da dose. Linzmeyer Júnior et al. (2008) observaram que com a elevação gradativa das doses de trinexapac-ethyl na cultura da soja ocorreu aumento do diâmetro do caule das plantas, além da redução na altura destas. 
Embora o diâmetro do colmo seja importante quando se trata da resistência ao acamamento, em trigo nem sempre há resposta do diâmetro do colmo à aplicação do regulador de crescimento, mesmo em cultivares altamente responsivos. Segundo Lozano \& Leaden (2002), a aplicação do trinexapac-ethyl interfere no diâmetro interno do colmo pelo espessamento do tecido esclerenquimático e causa maior resistência do colmo ao acamamento, porém esse espessamento interno pode ou não interferir no diâmetro externo do colmo, o que foi observado em vários trabalhos sobre cultura do trigo (Zagonel et al., 2002a; Penckowski, 2006; Berti et al., 2007).

A área foliar por planta não foi afetada pelo trinexapac-ethyl, independentemente da dose e da época de aplicação em ambos os híbridos utilizados (Tabelas 1 e 2). O índice de área foliar (IAF) não foi alterado pela época de aplicação do trinexapac-ethyl nos dois híbridos (Tabela 1). Em relação à dose do trinexapacethyl, não foi observada resposta do Status TL, mas, para o Maximus TLTG ocorreu resposta quadrática do IAF em relação à dose do produto, em que ocorreu leve aumento do IAF com o aumento da dose do trinexapac-ethyl (Tabela 2). Fernandes (2009), avaliando três cultivares de trigo, observou que uma delas respondeu com aumento da área foliar por planta em função do uso do trinexapac-ethyl, causado provavelmente pelo maior número de folhas verdes por planta e por alterações no tamanho das folhas promovidas pelo uso do regulador de crescimento, concluindo que o trinexapac-ethyl exerceu influência na área foliar de maneira indireta, pelos efeitos no número, comprimento e largura das folhas, e com intensidade variável com o cultivar. Resposta similar foi observada no presente trabalho, no qual somente para o híbrido Maximus TLTG houve efeito do regulador de crescimento no IAF (Tabela 2) e no comprimento da folha oposta à espiga (Tabela 4).

No híbrido Status TL, o comprimento das folhas oposta e superior à espiga não foi afetado pelas doses e épocas de aplicação do trinexapacethyl (Tabelas 3 e 4). Para o Maximus TLTG, não houve efeito da dose do trinexapac-ethyl na largura das folhas oposta e superior à espiga (Tabela 4). No entanto, para esse híbrido ocorreu aumento linear do comprimento e da
Tabela 3 - Largura (LFA) e comprimento (CFA) da folha acima da espiga e largura (LFO) e comprimento (CFO) da folha oposta à espiga do milho, Status TL e Maximus TLTG, em função de épocas de aplicação de trinexapac-ethyl. Ponta Grossa-PR, 2011

\begin{tabular}{|c|c|c|c|c|}
\hline \multirow{2}{*}{$\begin{array}{l}\text { Época de } \\
\text { aplicação }\end{array}$} & \multicolumn{4}{|c|}{ Status TL } \\
\hline & LFA $(\mathrm{cm})$ & $\mathrm{CFA}(\mathrm{cm})$ & LFO $(\mathrm{cm})$ & $\mathrm{CFO}(\mathrm{cm})$ \\
\hline $\mathrm{V} 2$ & $11,1 \mathrm{a}$ & $78,7 \mathrm{a}$ & $11,1 \mathrm{a}$ & $71,9 \mathrm{a}$ \\
\hline V4 & $11,3 \mathrm{a}$ & $78,6 \mathrm{a}$ & $10,8 \mathrm{a}$ & $71,3 \mathrm{a}$ \\
\hline V6 & $11,0 \mathrm{a}$ & $77,8 \mathrm{a}$ & $10,9 \mathrm{a}$ & $71,8 \mathrm{a}$ \\
\hline V8 & $11,2 \mathrm{a}$ & $78,1 \mathrm{a}$ & $11,0 \mathrm{a}$ & $70,8 \mathrm{a}$ \\
\hline CV $(\%)$ & 5,08 & 4,05 & 5,47 & 3,47 \\
\hline \multirow{2}{*}{$\begin{array}{l}\text { Época de } \\
\text { aplicação }\end{array}$} & \multicolumn{4}{|c|}{ Maximus TLTG } \\
\hline & LFA $(\mathrm{cm})$ & $\mathrm{CFA}(\mathrm{cm})$ & $\mathrm{LFO}(\mathrm{cm})$ & $\mathrm{CFO}(\mathrm{cm})$ \\
\hline $\mathrm{V} 2$ & $11,3 \mathrm{a}$ & $76,8 \mathrm{a}$ & $11,2 \mathrm{a}$ & $70,6 \mathrm{a}$ \\
\hline V4 & $11,2 \mathrm{a}$ & $76,3 \mathrm{a}$ & $11,1 \mathrm{a}$ & $70,7 \mathrm{a}$ \\
\hline V6 & $11,1 \mathrm{a}$ & $76,9 \mathrm{a}$ & $11,1 \mathrm{a}$ & $70,4 \mathrm{a}$ \\
\hline V8 & $11,8 \mathrm{a}$ & $76,6 \mathrm{a}$ & $11,5 \mathrm{a}$ & $70,6 \mathrm{a}$ \\
\hline $\mathrm{CV}(\%)$ & 5,6 & 4,4 & 5,6 & 3,4 \\
\hline
\end{tabular}

Médias seguidas da mesma letra minúscula não diferem significativamente pelo teste de Tukey $(\mathrm{p} \leq 5 \%)$; CV: coeficiente de variação.

Tabela 4 - Largura (LFA) e comprimento (CFA) da folha acima da espiga e largura (LFO) e comprimento (CFO) da folha oposta à espiga do milho, Status TL e Maximus TLTG, em função de doses de trinexapac-ethyl. Ponta Grossa-PR, 2011

\begin{tabular}{|c|l|c|}
\hline Status TL & \multicolumn{1}{|c|}{ Equação ou média } & $\mathrm{R}^{2}$ \\
\hline LFA $(\mathrm{cm})$ & $\hat{\mathrm{Y}}=11,2$ & $\mathrm{~ns}$ \\
\hline CFA $(\mathrm{cm})$ & $\hat{\mathrm{Y}}=78,4$ & $\mathrm{~ns}$ \\
\hline LFO $(\mathrm{cm})$ & $\hat{\mathrm{Y}}=10,9$ & $\mathrm{~ns}$ \\
\hline CFO $(\mathrm{cm})$ & $\hat{\mathrm{Y}}=71,5$ & $\mathrm{~ns}$ \\
\hline Maximus TLTG & \multicolumn{1}{|c|}{ Equação ou média } & $\mathrm{R}^{2}$ \\
\hline LFA $(\mathrm{cm})$ & $\hat{\mathrm{Y}}=11,12+0,208 \mathrm{x}$ & $80,6^{*}$ \\
\hline CFA $(\mathrm{cm})$ & $\hat{\mathrm{Y}}=78,90-1,958 \mathrm{x}$ & $88,1^{*}$ \\
\hline LFO $(\mathrm{cm})$ & $\hat{\mathrm{Y}}=11,2$ & $\mathrm{~ns}$ \\
\hline CFO $(\mathrm{cm})$ & $\hat{\mathrm{Y}}=73,09-4,129+1,083 \mathrm{x}^{2}$ & $98,1^{*}$ \\
\hline
\end{tabular}

ns: não significativo; ${ }^{*}$ significativo a $5 \%$ de probabilidade.

largura da folha acima da espiga pelo uso do regulador e uma resposta quadrática do comprimento da folha oposta à espiga, com tendência de diminuição do comprimento dessa folha com o aumento da dose do regulador (Tabela 4). Resposta similar foi observada por Fernandes (2009) na cultura do trigo, em que também se verificou aumento da largura das folhas e 
diminuição do comprimento destas quando do uso do trinexapac-ethyl, porém a redução do tamanho da folha é provavelmente um efeito indireto desse regulador, visto que este é conhecido pela redução na altura das plantas.

De acordo com Guimarães et al. (2002), na cultura do arroz o comprimento da folha é mais variável que a largura, estando isso associado com o ângulo foliar; quanto mais compridas forem as folhas, mais decumbentes elas são; assim, folhas curtas e estreitas estão associadas a folhas eretas. Folhas estreitas e curtas podem ser mais regularmente distribuidas do que folhas largas e compridas; a melhor distribuição delas aumenta a interceptação da radiação solar. Entretanto, as respostas do arroz e do trigo na interceptação da radiação foliar e arquitetura de plantas não podem ser extrapoladas de maneira segura para o milho, em razão não somente da grande diferença do tamanho das folhas, mas principalmente pela localização da espiga na planta, que rege a importância das folhas próximas à espiga no enchimento de grãos: as superiores, no caso do trigo e do arroz, e as da parte mediana das plantas (folhas próximas da espiga), no caso do milho.

$\mathrm{O}$ índice de acamamento (IA) é reflexo do número de plantas acamadas e seu ângulo de inclinação. Nos híbridos Status TL e Maximus
TLTG não foi observada diferença entre as doses e as épocas de aplicação do trinexapacethyl em relação ao acamamento, avaliado no estádio R3 e na pré-colheita (Tabelas 5 e 7).

Os tradicionais genótipos de trigo com estatura elevada foram selecionados, durante muitos anos, por sua habilidade em crescer rapidamente nos estádios iniciais de desenvolvimento. Esses genótipos competem eficientemente com as plantas daninhas; contudo, quando modernos métodos de produção, como a adubação nitrogenada, são usados, os resultados tendem a ser negativos, visto que isso pode causar o acamamento das plantas (Cruz et al., 2003). Os híbridos de milho utilizados neste trabalho são considerados resistentes ao acamamento e tiveram pequenas variações entre os tratamentos (Tabelas 5 e 7). $\mathrm{O}$ indice de acamamento observado foi de resistente (IA < 10) a moderadamente resistente (IA de 10,1 a 20,0) segundo a metodologia proposta por Sousa (1998) e utilizada para avaliar o acamamento dos híbridos.

A população final de plantas e o número de espigas por planta e de grãos por fileira não foram afetados pela época de aplicação e pela dose do trinexapac-ethyl nos híbridos Status TL e Maximus TLTG (Tabelas 5 e 7). Somente a massa de mil grãos respondeu de forma quadrática à dose no Status TL (Tabela 7). No

Tabela 5 - Índice de acamamento na fase de grão leitoso (IAR3) e em pré-colheita (IAPC), população final (PF), número de espigas por planta (EP), de grãos por fileiras (GF), de fileiras por espiga (FE) e massa de mil grãos (MMG) do milho, Status TL e Maximus TLTG, em função de épocas de aplicação de trinexapac-ethyl. Ponta Grossa-PR, 2011

\begin{tabular}{|c|c|c|c|c|c|c|c|}
\hline \multirow{2}{*}{ Época de aplicação } & \multicolumn{7}{|c|}{ Status TL } \\
\hline & IAR3 & IAPC & PF & EP & GF & $\mathrm{FE}$ & MMG (g) \\
\hline $\mathrm{V} 2$ & $16,2 \mathrm{a}$ & $14,7 \mathrm{a}$ & $69.565 \mathrm{a}$ & $1,8 \mathrm{a}$ & $25,8 \mathrm{a}$ & $15,8 \mathrm{a}$ & $203 \mathrm{a}$ \\
\hline V4 & $10,4 \mathrm{a}$ & $12,5 \mathrm{a}$ & $70.756 \mathrm{a}$ & $1,8 \mathrm{a}$ & $26,1 \mathrm{a}$ & $16,1 \mathrm{a}$ & $195 \mathrm{a}$ \\
\hline V6 & $16,0 \mathrm{a}$ & $9,7 \mathrm{a}$ & $66.561 \mathrm{a}$ & $1,8 \mathrm{a}$ & $26,1 \mathrm{a}$ & $15,7 \mathrm{a}$ & $201 \mathrm{a}$ \\
\hline V8 & $11,1 \mathrm{a}$ & $9,4 \mathrm{a}$ & $71.653 \mathrm{a}$ & $1,6 \mathrm{a}$ & $26,5 \mathrm{a}$ & $16,2 \mathrm{a}$ & $196 \mathrm{a}$ \\
\hline $\mathrm{CV}(\%)$ & 146,7 & 165,6 & 12,2 & 27,3 & 7,76 & 5,4 & 10,1 \\
\hline \multirow{2}{*}{ Época de aplicação } & \multicolumn{7}{|c|}{ Maximus TLTG } \\
\hline & IAR3 & IAPC & $\mathrm{PF}$ & EP & GF & $\mathrm{FE}$ & MMG (g) \\
\hline $\mathrm{V} 2$ & $4,6 \mathrm{a}$ & $7,7 \mathrm{a}$ & $60.156 \mathrm{a}$ & $2,0 \mathrm{a}$ & $29,0 \mathrm{a}$ & $17,4 \mathrm{a}$ & $224 \mathrm{a}$ \\
\hline V4 & $1,7 \mathrm{a}$ & $7,9 \mathrm{a}$ & $55.468 \mathrm{a}$ & $2,0 \mathrm{a}$ & $27,6 \mathrm{a}$ & $17,4 \mathrm{a}$ & $218 \mathrm{a}$ \\
\hline V6 & $4,1 \mathrm{a}$ & $6,6 \mathrm{a}$ & $63.281 \mathrm{a}$ & $1,8 \mathrm{a}$ & $28,6 \mathrm{a}$ & $17,6 \mathrm{a}$ & $227 \mathrm{a}$ \\
\hline V8 & $1,1 \mathrm{a}$ & $8,1 \mathrm{a}$ & $61.718 \mathrm{a}$ & $1,8 \mathrm{a}$ & $28,0 \mathrm{a}$ & $18,1 \mathrm{a}$ & $223 \mathrm{a}$ \\
\hline CV $(\%)$ & 255 & 99,1 & 17,3 & 17,0 & 6,7 & 6,2 & 9,6 \\
\hline
\end{tabular}

Médias seguidas da mesma letra minúscula não diferem significativamente pelo teste de Tukey ( $\leq \leq 5 \%$ ); $\mathrm{CV}$ : coeficiente de variação. 
trigo, em geral, a resposta dos componentes da produção à aplicação do trinexapac-ethyl está ligada às modificações que o produto causa na morfologia da planta, especialmente a redução de altura e arquitetura de plantas pelas folhas mais eretas, e quase sempre se reflete em aumento de produção. No entanto, vários autores observaram que, mesmo com as características morfológicas e a produtividade sendo afetadas, nem sempre há resposta de um componente da produção em especial (Zagonel et al., 2002b; Penckowski, 2006), visto que outros fatores, como adubação nitrogenada, densidade de semeadura e clima, também interferem nos componentes com maior ou menor intensidade conforme o ano de cultivo (Zagonel \& Fernandes, 2007). No caso do milho, a ausência de resposta ao trinexapac-ethyl ocorreu em razão de o produto não ter afetado de forma substancial a altura de plantas e outras características morfológicas da planta.

A produtividade não foi alterada pelo trinexapac-ethyl aplicado em diferentes épocas e doses (Tabelas 6 e 7). Em geral, na cultura do trigo há resposta de produtividade quando outras características das plantas são afetadas, como a altura de plantas e mudanças na arquitetura foliar, o que garante melhor atividade fotossintética da planta (Zagonel \& Fernandes, 2007). No entanto, em alguns trabalhos foi observado que, mesmo com essas modificações, nem sempre há resposta de produtividade do trigo e que esta está aliada ao cultivar utilizado. Também foi constatado que a dose do trinexapac-ethyl deve ser adequada ao cultivar quando se espera aumento de produtividade (Zagonel \& Fernandes, 2007). Assim, a ausência de resposta dos híbridos de

Tabela 6 - Produtividade do milho $\left(\mathrm{kg} \mathrm{ha}^{-1}\right)$, Status TL e Maximus TLTG, em função de épocas de aplicação de trinexapacethyl. Ponta Grossa-PR, 2011

\begin{tabular}{|c|c|c|}
\hline Época de aplicação & Status TL & Maximus TLTG \\
\hline V2 & $7.581 \mathrm{a}$ & $7.648 \mathrm{a}$ \\
\hline V4 & $7.966 \mathrm{a}$ & $7.668 \mathrm{a}$ \\
\hline V6 & $7.458 \mathrm{a}$ & $8.119 \mathrm{a}$ \\
\hline V8 & $7.871 \mathrm{a}$ & $8.148 \mathrm{a}$ \\
\hline CV (\%) & 15,2 & 14,3 \\
\hline
\end{tabular}

Médias seguidas da mesma letra minúscula não diferem significativamente pelo teste de Tukey $(\mathrm{p} \leq 5 \%) ; \mathrm{CV}$ : coeficiente de variação.
Tabela 7 - Índice de acamamento na fase de grão leitoso (IAR3) e em pré-colheita (IAPC), número de fileiras por espiga (FE) e de espigas por planta (EP), população final (PF), número de grãos por fileiras (GF) e de fileiras por espiga (FE), massa de mil grãos (MMG) e produtividade (PROD) do milho, Status TL e Maximus TLTG, em função de diferentes doses de trinexapac-ethyl. Ponta Grossa-PR, 2011

\begin{tabular}{|l|l|c|}
\hline \multicolumn{1}{|c|}{ Status TL } & \multicolumn{1}{|c|}{ Equação ou média } & $\mathrm{R}^{2}$ \\
\hline IAR3 & $\hat{\mathrm{Y}}=13,4$ & $\mathrm{~ns}$ \\
\hline IAPC & $\hat{\mathrm{Y}}=11,5$ & $\mathrm{~ns}$ \\
\hline FE & $\hat{\mathrm{Y}}=15,9$ & $\mathrm{~ns}$ \\
\hline EP & $\hat{\mathrm{Y}}=1,7$ & $\mathrm{~ns}$ \\
\hline PF & $\hat{\mathrm{Y}}=69.214$ & $\mathrm{~ns}$ \\
\hline GF & $\hat{\mathrm{Y}}=26,2$ & $\mathrm{~ns}$ \\
\hline MMG $(\mathrm{g})$ & $\hat{\mathrm{Y}}=192,2+291,67 \mathrm{x}-133,334 \mathrm{x}^{2}$ & $89,1^{*}$ \\
\hline PROD $\left(\mathrm{kg} \mathrm{ha}{ }^{1}\right)$ & $\hat{\mathrm{Y}}=7.719$ & $\mathrm{~ns}$ \\
\hline Maximus TLTG & & $\mathrm{R}$ \\
\hline IAR3 & $\hat{\mathrm{Y}}=5,3$ & $\mathrm{~ns}$ \\
\hline IAPC & $\hat{\mathrm{Y}}=7,6$ & $\mathrm{~ns}$ \\
\hline FE & $\hat{\mathrm{Y}}=17,6$ & $\mathrm{~ns}$ \\
\hline EP & $\hat{\mathrm{Y}}=1,9$ & $\mathrm{~ns}$ \\
\hline PF & $\hat{\mathrm{Y}}=61093,7-11770,83 \mathrm{x}+6250,00 \mathrm{x}^{2}$ & $89,1^{*}$ \\
\hline GF & $\hat{\mathrm{Y}}=29,13-0,742 \mathrm{x}$ & $95,0^{*}$ \\
\hline MMG $(\mathrm{g})$ & $\hat{\mathrm{Y}}=223$ & $\mathrm{~ns}$ \\
\hline PROD $\left(\mathrm{kg} \mathrm{ha}^{-1}\right)$ & $\hat{\mathrm{Y}}=7.896$ & $\mathrm{~ns}$ \\
\hline
\end{tabular}

ns: não significativo; ${ }^{*}$ significativo a $5 \%$ de probabilidade.

milho ao trinexapac-ethyl está mais ligada aos poucos efeitos que o produto causou nas plantas, porém não se deve desconsiderar que a resposta também é dependente do híbrido.

Diante dos resultados obtidos, conclui-se que a época de aplicação do trinexapac-ethyl não afetou as características agronômicas e a produtividade dos dois híbridos de milho. No que se refere à dose do regulador, somente o Maximus TLTG mostrou aumento da largura e diminuição do comprimento das folhas com o incremento da dose do produto, sem efeitos substanciais nos componentes da produção e na produtividade. Ao contrário do trigo, o uso do trinexapac-ethyl na cultura do milho deve ser mais bem avaliado, especialmente em relação à dose do produto e à reação de híbridos. 


\section{LITERATURA CITADA}

BERTI, M.; ZAGONEL, J.; FERNANDES, E. C

Produtividade de cultivares de trigo em função do trinexapacethyl e doses de nitrogênio. Sci. Agr., v. 8, n. 2, p. 127-134, 2007.

COSTA, N. V. et al. Características morfológicas de gramas em resposta à aplicação de trinexapac-ethyl.

Planta Daninha, v. 27, n. 1, p. 113-122, 2009.

CRUZ, J. C.; PEREIRA FILHO, I. A.; SILVA, G. H. Oferta abundante. Cultivar Grandes Culturas, p. 18-33, 2010. (Especial Milho).

CRUZ, P. J. et al. Influência do acamamento sobre o rendimento de grãos e outros caracteres em trigo. R. Bras. Agroci., v. 9, n. 1, p. 5-8, 2003.

DAVIES, P. J. The plant hormones: their nature, occurrence, and functions. In: DAVIES, P. J. Plant hormones and their role in plant growth and development. Nethrlands: Kluwer Academic, 1987. p. 1-23.

DOURADO NETO, D. et al. Aplicação e influência do fitorregulador no crescimento das plantas de milho. R. FZVA, v. 11, n. 1, p. 1-9, 2004.

DUETE, R. R. C. et al. Manejo da adubação nitrogenada e utilização do nitrogênio $\left({ }^{15} \mathrm{~N}\right)$ pelo milho em Latossolo Vermelho. R.Bras. Ci. Solo, v. 32, n. 1, p. 161-171, 2008

ESPINDULA, M. C. et al. Efeitos de reguladores de crescimento na elongação do colmo de trigo. Acta Sci. Agron., v. 32 , n. 1, p. $109-116,2010$

FERNANDES, E. C. População de plantas e regulador de crescimento afetando a produtividade de cultivares de trigo. 2009. 99 f. Dissertação (Mestrado em Agronomia) Universidade Estadual de Ponta Grossa, Ponta Grossa, 2009.

FIALHO, C. M. T. et al. Caracteres morfoanatômicos de Brachiaria brizantha submetida à aplicação de trinexapacethyl. Planta Daninha, v. 27, n. 3, p. 533-539, 2009.

GUIMARÃES, C. M.; FAGERIA, N. K.; BARBOSA

FILHO, M. P. Como a planta de arroz se

desenvolve. Potafos, v.13, n. 99, p. 1-12, 2002.
LINZMEYER JUNIOR, R. et al. Influência de retardante vegetal e densidades de plantas sobre o crescimento, acamamento e produtividade da soja. Acta Sci. Agron., v. 30, n. 3, p. 373-379, 2008.

LOZANO, C. M.; LEADEN, M. I. Efecto de reguladores de crecimiento sobre el rendimiento y altura en dos cultivares de trigo. In: CONGRESSO NACIONAL DE TRIGO, 5. SIMPÓSIO NACIONAL DE CEREALES DE SIEMBRA OTOÑO INVERNAL, 3. Argentina, Inta, 2002. Disponível em: <http://www.inta.gov.ar/balcarce/info/documentos/ posters/5/leaden.htm>. Acesso em: 12 ago. 2011.

MUNDSTOCK, C. M. Cultivo de cereais de estação fria Porto Alegre: NBS, 1983. 265 p

PENCKOWSKI, L. H. Efeitos do trinexapac-ethyl e do nitrogênio na produtividade da cultura do trigo. Ponta Grossa: 2006. 84 f. Dissertação (Mestrado em Agronomia) Universidade Estadual de Ponta Grossa, Ponta Grossa, 2006.

RADEMACHER, W. Growth retardants: effects on gibberellin biosynthesis and other metabolic pathways. Ann. Rev. Plant Physiol. Plant Molec. Biol., v. 51, n. 1, p. 501-531, 2000.

RAJALA, A. Plant growth regulators to manipulate cereal growth in Northern growing conditions. 2003. $53 \mathrm{f}$. Dissertation (Academic) - Faculty of Agriculture and Forestry, University of Helsinki, Helsinki, 2003. Disponível em: $<$ http://ethesis.helsin-ki.fi/julkaisut/maa/sbiol/vk/rajala/ plantgro.pdf $>$. Acesso em: 7 mar. 2011.

SOUSA, C. N. A. O acamamento e a reação de cultivares de trigo recomendadas no Rio Grande do Sul. Pesq. Agropec. Bras., v. 33, n. 5, p. 537-541, 1998

ZAGONEL, J.; VENANCIO, W. S.; KUNZ, R. P. Efeito de regulador de crescimento na cultura do trigo submetido a diferentes doses de nitrogênio e densidades de plantas. Planta Daninha, v. 20, n. 3, p. 471-476, 2002a.

ZAGONEL, J. et al. Doses de nitrogênio e densidade de plantas com e sem um regulador de crescimento afetando o trigo, cultivar OR-1. Ci. Rural, v. 23, n. 1, p. 25-29, 2002b

ZAGONEL, J.; FERNANDES, E. C. Doses e épocas de aplicação de redutor de crescimento afetando cultivares de trigo em duas doses de nitrogênio. Planta Daninha, v. 25, n. 2, p. 331-339, 2007. 